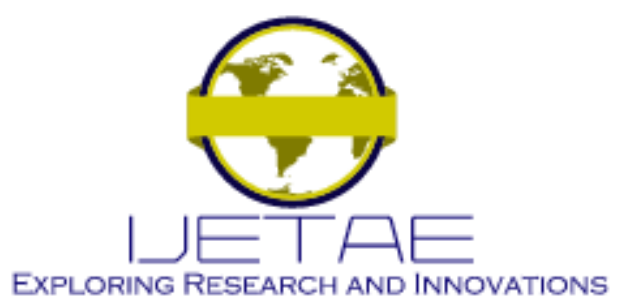

International Journal of Emerging Technology and Advanced Engineering

Website: www.ijetae.com (E-ISSN 2250-2459, Scopus Indexed, ISO 9001:2008 Certified Journal, Volume 11, Issue 11, November 2021)

Manuscript Received: 01 October 2021, Received in Revised form: 31 October 2021, Accepted: 05 November 2021

DOI: 10.46338/ijetae1121_11

\title{
Diagnosis of Mechanical Faults Affecting a Hydroelectric Group by Vibration Analysis
}

\author{
Mohammed Bouaicha ${ }^{1}$, Mariya Guerroum ${ }^{2}$, Imad El Adraoui ${ }^{3}$, Hassan Gziri ${ }^{4}$, Abdelhafid Ait Elmahjoub ${ }^{5}$, Mourad \\ Zegrari $^{6}$ \\ ${ }^{1,5,6}$ Laboratory of Structural Engineering, Intelligent, and Electrical Energy (ISSIEE), The National Higher School of Arts \\ and Crafts (ENSAM), Hassan II University, Mers Sultan BP 916, Casablanca, Morocco \\ ${ }^{2}$ Innovation Lab for Operations (ILO), Mohammed VI Polytechnic University, Hay Moulay Rachid, Benguerir, 43150, Morocco \\ ${ }^{3,4}$ Laboratory of Engineering, Industrial Management and Innovation (IMII), The Faculty of Sciences and Technology, Hassan \\ 1 st University, PO Box 577, Settat, Morocco
}

\begin{abstract}
This article deals with a diagnostic approach based on a predictive / conditional maintenance approach of a hydroelectric group. The technique used is based on the spectral analysis of the vibration signals, as well as on the orbital analysis of the bearings displacements. To do this, test protocols in different operating regimes are carried out, based on the collection of data measured according to the multisensor approach, the aim of which is to identify the predominant faults. The positions of the sensors are placed as close as possible to the bearings on the rigid structure of the hydroelectric group in accordance with the recommendations of standard ISO 10816-5. The evaluation approach is based on the analysis of the amplitudes of the vibration speeds, the aim of which is to identify the type of faults, as well as on the bearing displacement indicators in order to classify them in the pre-established zones according to thresholds recommended by the Standard. Therefore, a recommended tuning intervention can be planned in order to restore the unit to its proper operating condition, the aim of which is to increase its service life and improve fuel efficiency.
\end{abstract}

Keywords-Diagnostic, Vibration analysis, Hydroelectric group, Multi-sensor approach, Standard.

\section{INTRODUCTION}

Advances in the design and manufacture of rotating machines have given rise to increasingly efficient machines. As their specific power is constantly increasing, they must pass through several critical speeds when speeding up and slowing down. The machines are not ideal and have defects, related to manufacturing and operating conditions, which cause significant vibrations.
Manufacturers and operators in collaboration with research laboratories try to minimize them in order to increase the life of the machines, optimize their efficiency and ensure their regularity of operation, based on diagnostic techniques.

In the literature, several diagnostic techniques have been introduced for monitoring the state of health of rotating machines, using information collected by sensors, in particular accelerometers for measuring vibrations.

In the context of collecting the information, the authors in [1] have developed a method of implementing Condition-based Maintenance by Vibration Analysis (CMVA), to avoid failure problems. To do this, they relied on a thirty-year database within a large chemical industry company, via a collective technique known as Diagnostic Court Autonome (DCA). Finally, a summary was prepared proposing a general and structured approach which consists of five stages, namely: feasibility study, inventory, preparation stage, implementation stage and improvement and evaluation stage. More deeply, methods are developed in the literature, such as the method based on the Decomposition in Empirical Mode (MED), this technique is considered for the processing of the nonstationary and nonlinear signals. However, this EMD method remains limited in terms of performance. For this, the Local Mean Decomposition approach (LMD) reveals better performance in terms of fault diagnosis on a gearbox [2].

In addition, a study is proposed in [3], the researchers aim at the Decomposition in Variational Mode (MVD) of the signals, for an effective diagnosis of failure of bearings. 


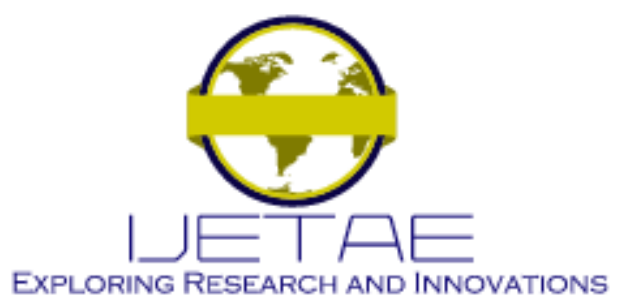

International Journal of Emerging Technology and Advanced Engineering

Website: www.ijetae.com (E-ISSN 2250-2459, Scopus Indexed, ISO 9001:2008 Certified Journal, Volume 11, Issue 11, November 2021)

A summary of the results shows a reduction in the noise effect and an improvement in the calculation accuracy of the MVD. In the same context, a model (CSMM) is proposed in [4] which consists in schematizing by interpolation and resampling for the improvement of the resolution of the collected signals and the localization of a band of optimum scale for subsequent detection of the bearing fault. In [5], a characterization study of bearing defect aims to reflect it by geometric structures based on vibration signals. To do this, the authors proposed a multiscale autocorrelation approach to detect signals indicating defects. These signals are used later in treatment to assess the health of a bearing for follow-up and monitoring [6]. Thus, in [7], one proposed method is to transform a vibration signal from healthy and defective bearings into the Teager-Kaiser domain and present it with energy-based statistical data. Two classifiers, namely: an LS-SVM classifier, a classifier based on neural networks, are used in the diagnostic step which reveals the superiority of the features of the Teager-Kaiser domain to those based on the time signal. Another tensor classifier (Support Tensor Machine with Dynamic Penalty Factors DC-STM) has been proposed by [8] for the diagnosis of rotating machines.

The techniques based on the Hidden Markov Model (HMM), they are used to identify the wear condition of a cutting tool in real time, by collecting information about the torque and cutting force during cutting a drilling operation [9]. Other techniques in research work, they are based on a diagnosis using the multi-sensor method. This approach is dedicated to complex systems. For example, the work treated in [10] proposes a multi-sensor information fusion approach based on Deep Convolutional Neural Networks (DCNN) to diagnose a failure on an experimental planetary gearbox. Another study was carried out to detect the oil vortex based on information collected by several sensors. The technique was based on the use of a sensor installed in the bearing housing and two probes on each bearing, for measuring load fluctuations during operation. The aim of this study is to follow the evolution of the oil film pressure caused by the vortex [11].

These vibration analysis-based approaches mentioned earlier ignore phase information and kinematic characteristics of rotating machines, hence the need for an additional source of information.
A study developed in [12], the authors introduced a data source characterizing the orbit of the shaft to classify the various faults associated with rotor imbalance. The information is extracted via probes for the measurement of displacements.

In the context of the approach based on vibration analysis, treated in the literature, this research article aims to diagnose the faults and displacements associated with a hydroelectric group producing electric power. The approach will be based on sensors (Accelerometers) for measuring vibrations and probes for measuring the displacement of bearings.

This paper is subdivided into three parts: materials and method, results / discussion and conclusion.

\section{MATERIALS AND METHODS}

\section{A. Presentation of the hydroelectric group}

A hydroelectric power station is defined as an installation for transforming the hydraulic energy of a watercourse or a water reservoir (dam) into electrical energy. It is made up of four essential elements:

- Water intake structures: The shape and dimensions of this structure are adapted to the nature of the terrain or to the conformation of the bed of the watercourse;

- Supply and loading structures: A supply channel, made of earth or concrete, and the penstock, most often made of steel or polyethylene, direct water to the power plant;

- Production equipment (hydroelectric group): A turbine transforms the energy supplied by the waterfall into mechanical energy. A generator produces electrical energy from the mechanical energy of the turbine;

- Restitution structures: At the outlet of the power plant, the turbined water is returned through a tailrace channel.

A hydroelectric group generally consists of (see Figures 1 and 2):

- A generator which consists of producing electrical energy using mechanical energy;

- A stator which designates the fixed part of the group;

- A rotor which designates the mobile part of the group;

- A turbine which designates the rotating device, the purpose of which is to convert the energy of the fluid, into mechanical energy using the blades; 


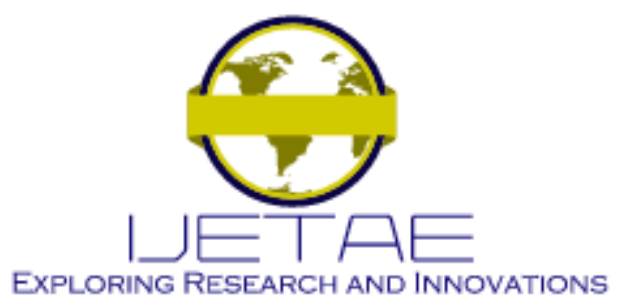

International Journal of Emerging Technology and Advanced Engineering

Website: www.ijetae.com (E-ISSN 2250-2459, Scopus Indexed, ISO 9001:2008 Certified Journal, Volume 11, Issue 11, November 2021)

- Adjustable valves which designate the devices for regulating the flow of fluid at the inlet of the turbine;

- A turbine blade which designates the hydrodynamic device for converting motive energy;

- An axis of rotation which designates the device, the purpose of which is to drive the turbine and the generator.

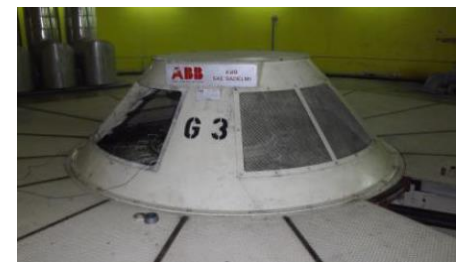

Figure 1 Hydroelectric group [13]

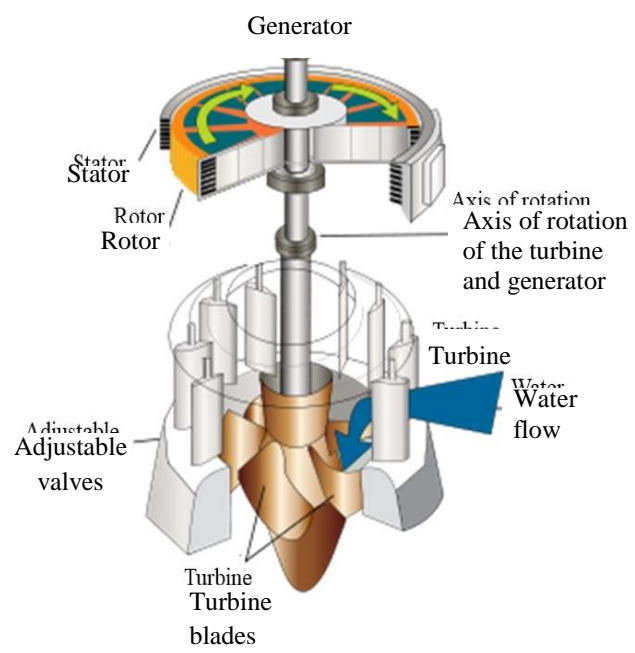

Figure 2 Essential elements of a hydroelectric group [13]

The Table I describes the characteristics of the hydroelectric group.
TABLE I

CHARACTERISTICS OF THE HYDROELECTRIC GROUP [13]

\begin{tabular}{|l|l|}
\hline Type & Francis \\
\hline Axis & Vertical \\
\hline Rotation speed & $333 \mathrm{rpm}$ \\
\hline Power & $80 \mathrm{MW}$ \\
\hline Number of blades & 17 \\
\hline Number of guide bearings & 2 \\
\hline $\begin{array}{l}\text { Number of bearing or pivot } \\
\text { bearings }\end{array}$ & 1 \\
\hline Number of directors & 24 \\
\hline Number of poles & 18 \\
\hline Alternator bearing clearances & $460 \mu \mathrm{m}$ \\
\hline Intermediate level clearances & $460 \mu \mathrm{m}$ \\
\hline Turbine bearing clearances & $420 \mu \mathrm{m}$ \\
\hline
\end{tabular}

\section{B. Defaults}

Rotating machines, for example the hydroelectric group, are never perfect, because they have defects due to manufacturing, functional play, fatigue, environment, installation, etc. These faults are the source of more or less vibrations and which will be the cause of long-term failures. The analysis of these vibrations is an important diagnostic tool in a maintenance strategy.

The vibrations appear, caused by excitations coming from the moving organs. Part of the energy is dissipated in the structure in the form of vibrations. As the machine ages, parts become deformed and slight changes in their dynamic properties appear. Shafts become misaligned, bearings and bearings wear out, rotors become unbalanced, clearances increase. All of these factors result in an increase in vibrational energy and therefore a decrease in effective energy. The advantage of vibration signals is to be able to access, by means of suitable processing, the characterization of dynamic forces, and particularly those resulting from abnormal excitations.

To evaluate these defects, research work is carried out in this direction, such as [14], the authors used the vibration analysis tool to identify the types of defects, namely: a rolling bearing defect, a plain bearing defect, electrical machine defect, flexible coupling defect. 


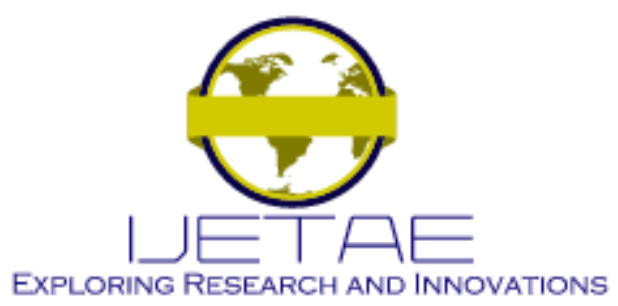

International Journal of Emerging Technology and Advanced Engineering

Website: www.ijetae.com (E-ISSN 2250-2459, Scopus Indexed, ISO 9001:2008 Certified Journal, Volume 11, Issue 11, November 2021)

Another study established in [15], to diagnose an unbalance defect on a vibration test bench. The authors collected several signals using a piezoelectric sensor (accelerometer) under constant / varying operating conditions. A method for diagnosing imbalance faults in a rotor based on the Deep Belief Network (DBN) approach. Heterogeneous data from multi-sensors represented by vibration signals and shaft displacement orbit plots [16]. However, the vibration-based fault identification (VFI) approach established on a rotating machine with a particular foundation cannot be applied to another identical machine installed on a different foundation, this is due to the different dynamic behavior of the machines provisions of foundations [17].

A study carried out in [18] for an improvement in the energy efficiency of double rotor structures, in particular, aircraft engines. To do this, a dynamic model established numerically by the Runge-Kutta method with coupling defects between unbalance and misalignment. The simulated vibration responses under different conditions, i.e., mass eccentricity, different rotational angular speeds, parallel and angular misalignment are analyzed by a waterfall plot. The experimental validity of the simulated model is verified on a twin-rotor test bench.

In what follows, a presentation of the methodology based on the literature which aims to identify the defects mentioned above by analysis of the frequency spectra of the vibration signals (accelerometers) and the displacements of the bearings (displacement probes).

\section{Instrumentation and Methodology}

The measurement of vibrations and movements of the bearings of the hydroelectric group is carried out according to the multi-sensor approach by installing the following sensors:

- Three accelerometers on each landing in the Upstream (Am), Right Bank (RD) and Axial (Ax) directions (points 1 to 9);

- Two displacement probes for each landing in the Upstream (Am) and Right Bank (RD) directions at $90^{\circ}$ (points 10 to 15 ).

The locations of these sensors are shown in figure 3 . The hydroelectric group contains three stages:

- A turbine bearing (PTU);

- An upper alternator bearing (PAS);

- A lower alternator bearing (PAI).

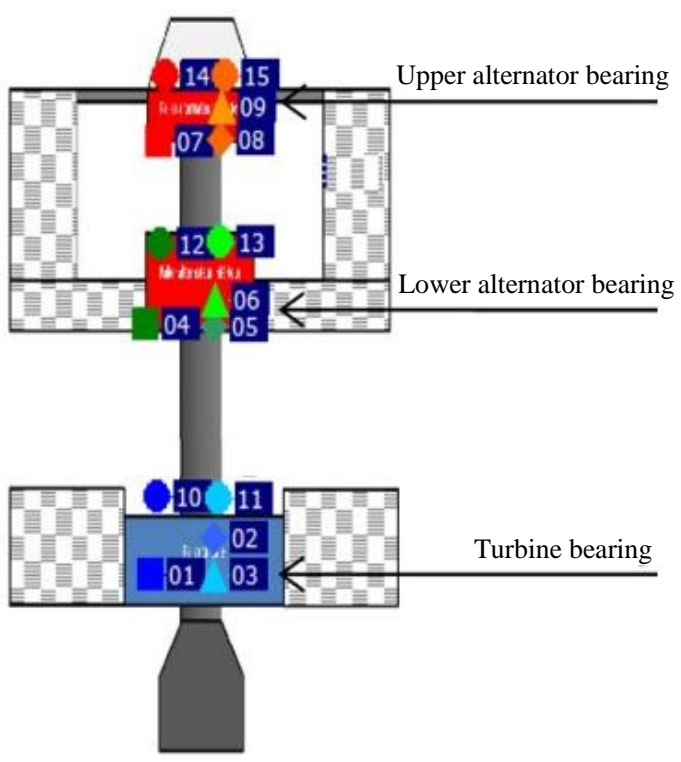

Figure 3 Location of the measuring points [13]

The Table II describes the location of the sensors in each point and thus its associated direction.

TABLE II

SENSOR NUMBER, EMPLACEMENT, AND DIRECTION [13]

\begin{tabular}{|l|l|l|}
\hline Sensor number & Emplacement & Direction \\
\hline 01 & PTU & Am \\
\hline 02 & PTU & RD \\
\hline 03 & PTU & Ax \\
\hline 04 & PAI & Am \\
\hline 05 & PAI & RD \\
\hline 06 & PAI & Ax \\
\hline 07 & PAS & Am \\
\hline 08 & PAS & RD \\
\hline 09 & PAS & Ax \\
\hline 10 & PTU & Am \\
\hline 11 & PTU & RD \\
\hline 12 & PAI & Am \\
\hline 13 & PAI & RD \\
\hline 14 & PAS & Am \\
\hline 15 & PAS & RD \\
\hline
\end{tabular}

The tests were carried out at nominal rotation speed of $333 \mathrm{rpm}$ according to the following operating protocols:

- MAVNE: Signature in idle operation not excited;

- MAVEX: Signature in excited idle mode; 


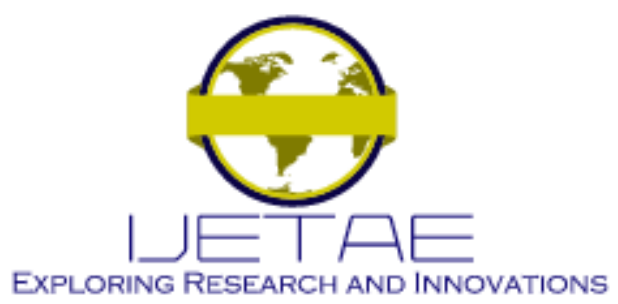

International Journal of Emerging Technology and Advanced Engineering

Website: www.ijetae.com (E-ISSN 2250-2459, Scopus Indexed, ISO 9001:2008 Certified Journal, Volume 11, Issue 11, November 2021)

- MQUART: Signature at $20 \mathrm{MW}$;

- MDEMI: Signature at $40 \mathrm{MW}$;

- MDEMI + Q: Signatures at half load with supply of reagent;

- $\quad$ MDEMI $-\mathrm{Q}:$ Signatures at half load with reagent absorption.

- M3QUARTS: Signature at $60 \mathrm{MW}$;

- MPMAX: Signature at full load (80 MW).

The results of the tests will be used to carry out a diagnosis of:
- Vibration signals to identify the type of fault according to spectral analysis [19];

- Orbits to determine the displacement thresholds at the level of the bearings according to the ISO 7919-5 [20] standard.

The Table III represents a non-exhaustive list of the defaults of rotating machines.

TABLE III

DEFAULTS OF ROTATING MACHINES

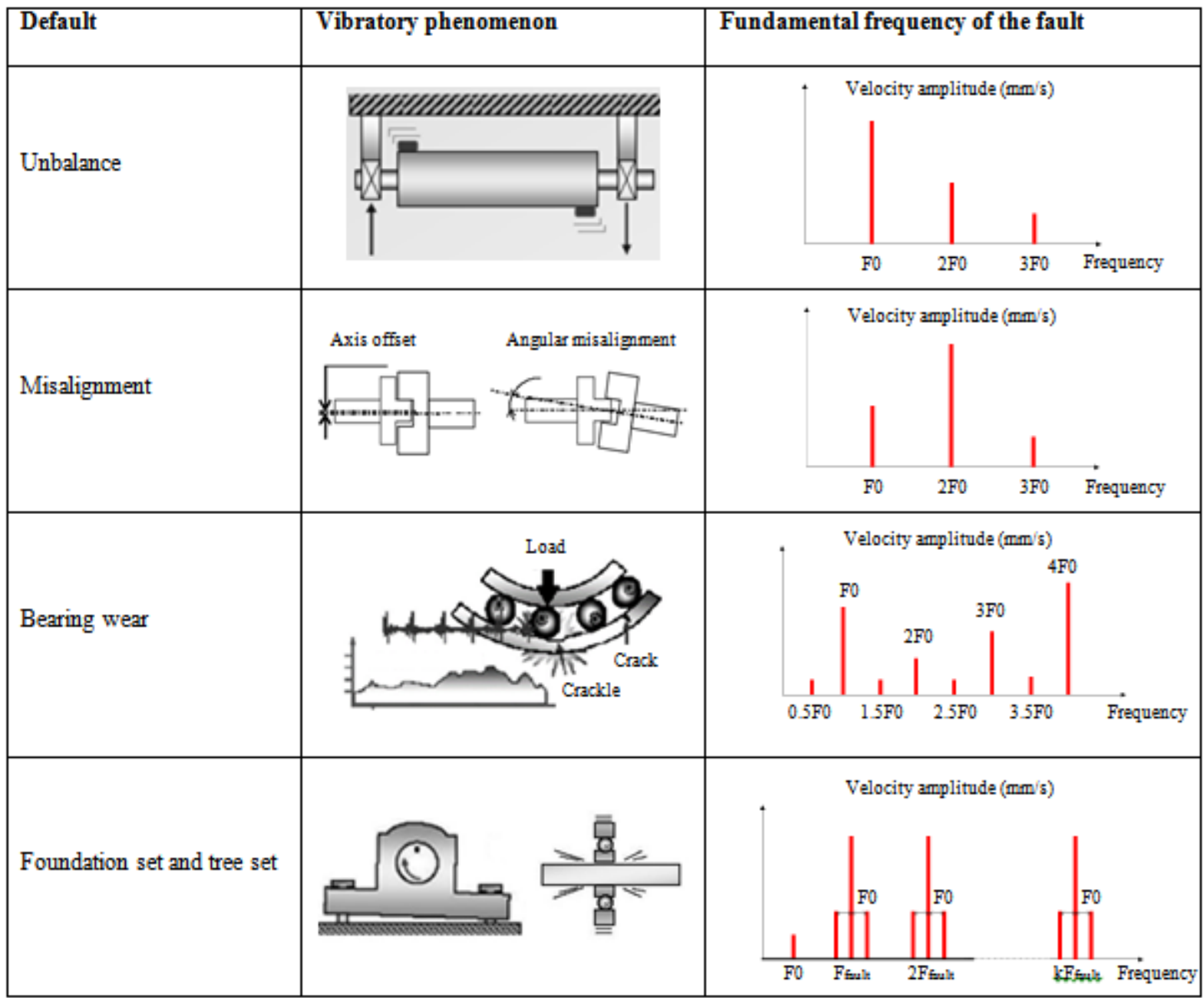




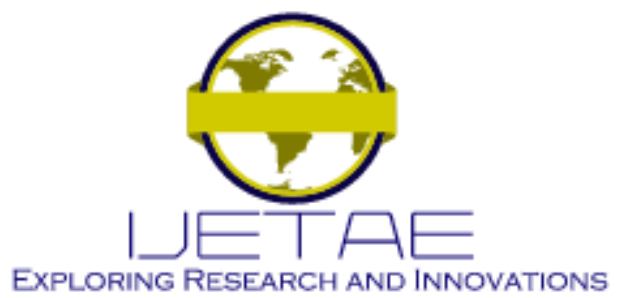

International Journal of Emerging Technology and Advanced Engineering

Website: www.ijetae.com (E-ISSN 2250-2459, Scopus Indexed, ISO 9001:2008 Certified Journal, Volume 11, Issue 11, November 2021)

With:

- $\mathrm{F}_{0}$ : Rotation frequency;

- Ffault= BPFI or BPFO or FTF or BSF ;

- $\quad$ BPFO : Ball Pass Freuency Outer Race;

- BPFI: Ball Pass Freuency Inner Race;

- FTF: Fondamental 1 train Freuency;

- BSF: Ball Spin Freuency.

\section{RESUlTS AND DisCUSSION}

At the beginning of this part, a vibration analysis was adopted, based on the spectral diagrams, to identify the type of fault associated with the rotor of the hydroelectric group, namely the turbine and the alternator.
Figures: 4, 5, 6, 7, 8, 9, 10 and 11 illustrate the type of "unbalance" fault, on all the bearings, which manifests itself by the amplitude of vibration at the predominant frequency $\left(\mathrm{F}_{0}\right)$,as well as harmonics at 2 times and 3 times the frequency of rotation $\left(2 \mathrm{~F}_{0}\right.$ and $\left.3 \mathrm{~F}_{0}\right)$.

By in-depth analysis, a misalignment is observed at the level of the upper alternator bearing (PAS), which is revealed by a predominant vibration amplitude peak at $2 \mathrm{~F}_{0}$ (sometimes $3 \mathrm{~F}_{0}$ ) at the level of the "9 Ax + PAS" sensor, during the MAVNE, MQUART and MPMAX operating modes observed respectively in Figures: 4, 6 and 11.
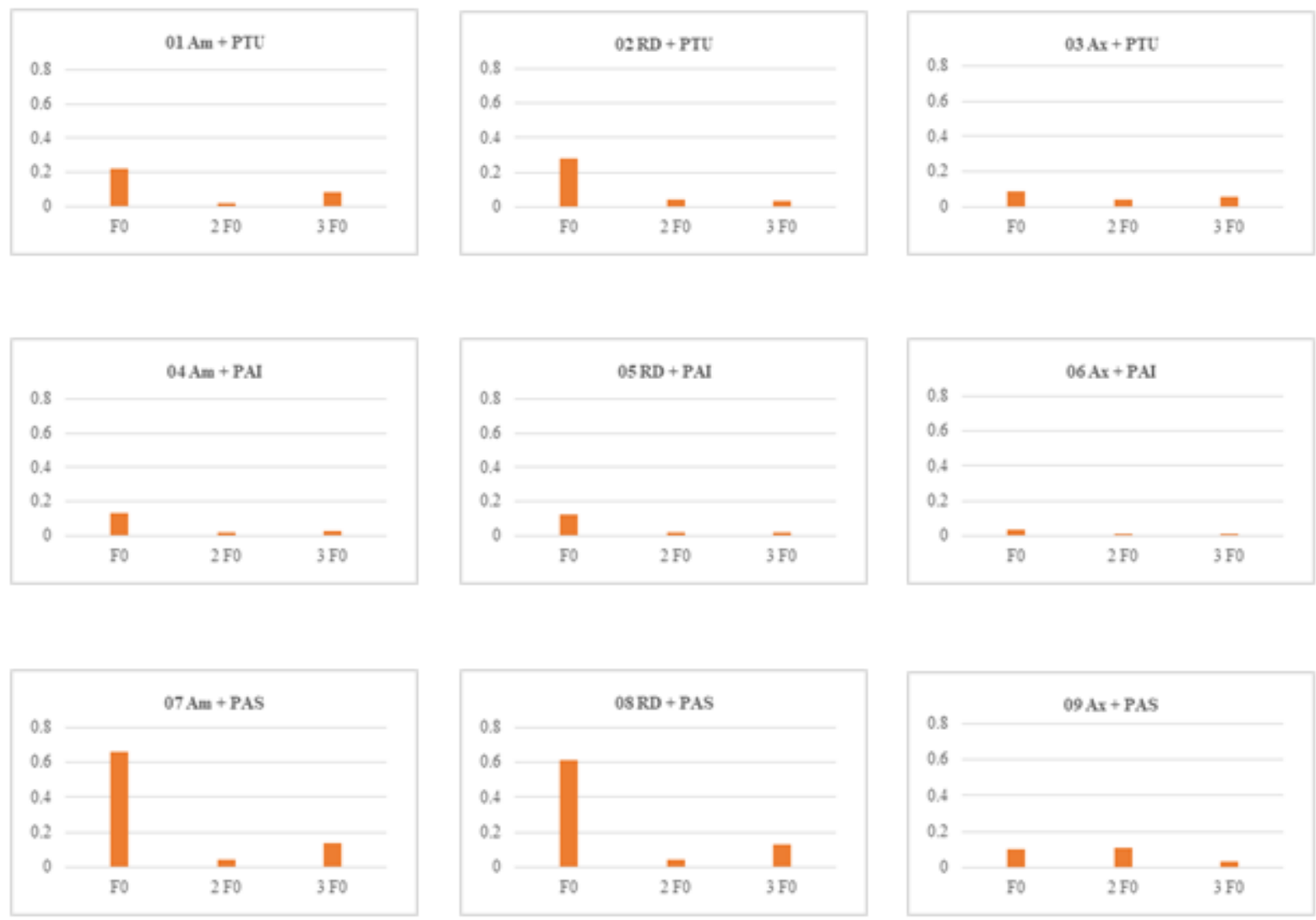

Figure 4 Real vibration spectra $(\mathrm{mm} / \mathrm{s})$ in MAVNE mode 


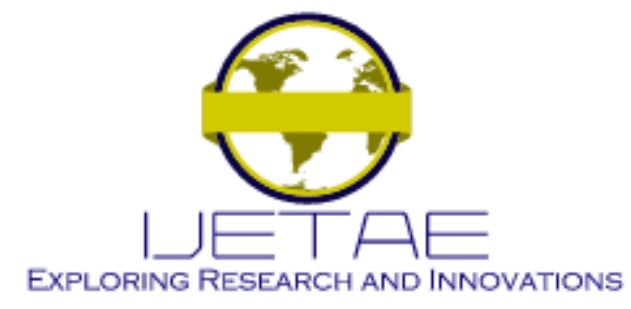

International Journal of Emerging Technology and Advanced Engineering

Website: www.ijetae.com (E-ISSN 2250-2459, Scopus Indexed, ISO 9001:2008 Certified Journal, Volume 11, Issue 11, November 2021)
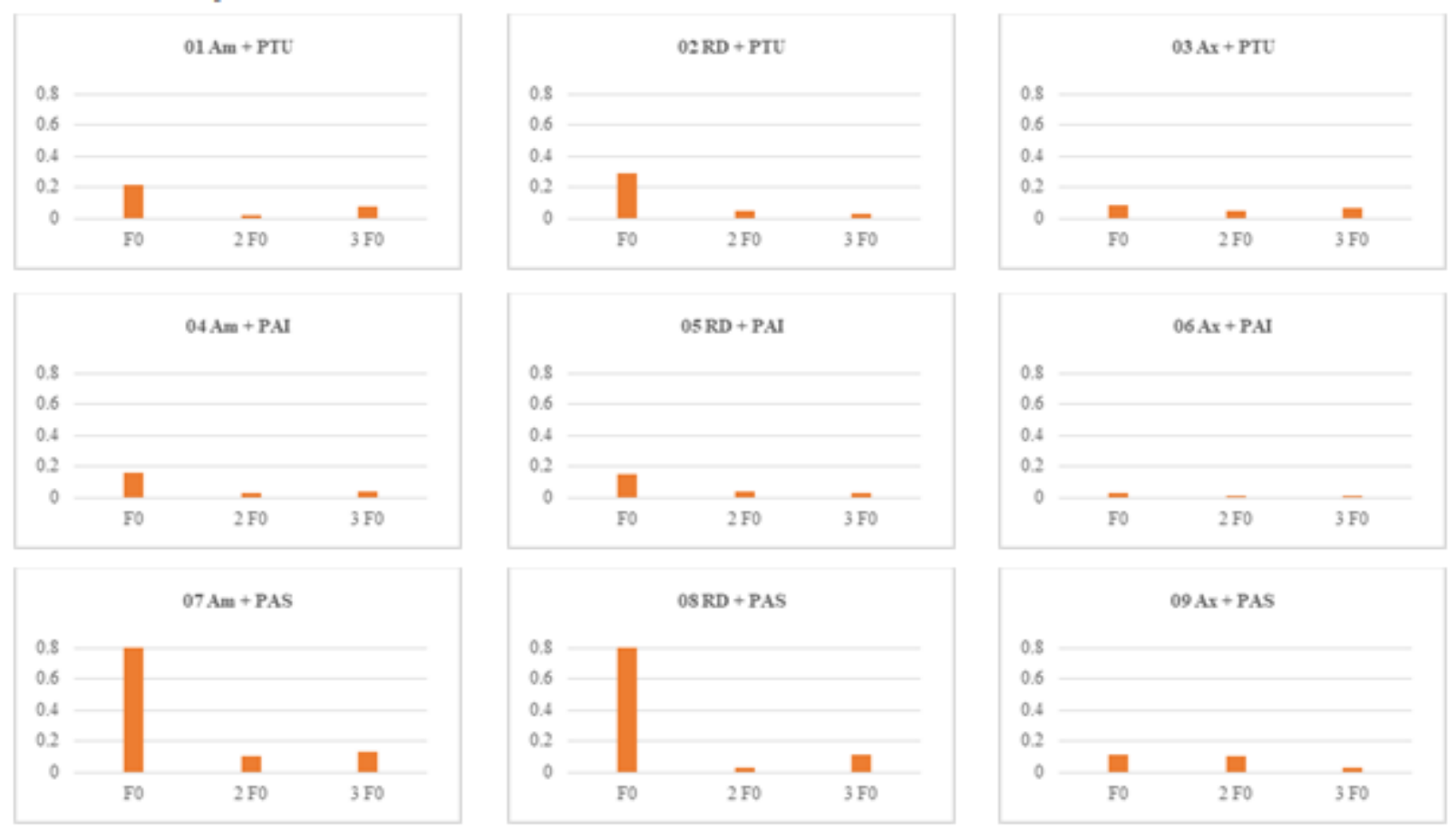

Figure 5 Real vibration spectra $(\mathrm{mm} / \mathrm{s})$ in MAVEX mode
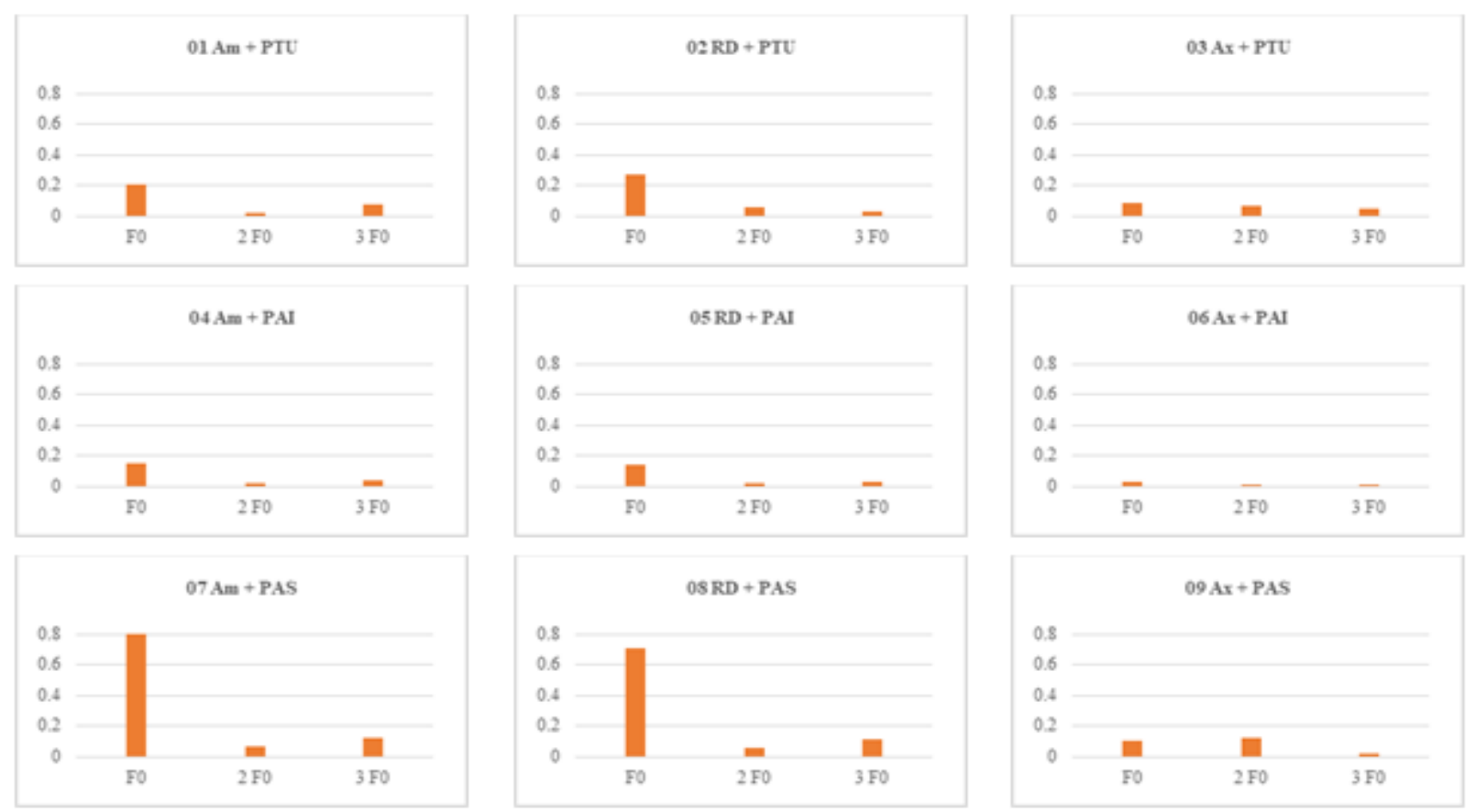


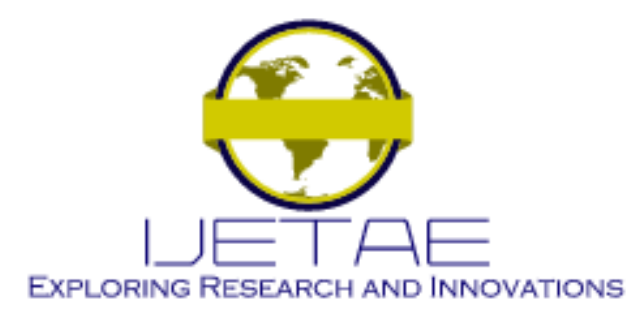

International Journal of Emerging Technology and Advanced Engineering

Website: www.ijetae.com (E-ISSN 2250-2459, Scopus Indexed, ISO 9001:2008 Certified Journal, Volume 11, Issue 11, November 2021)
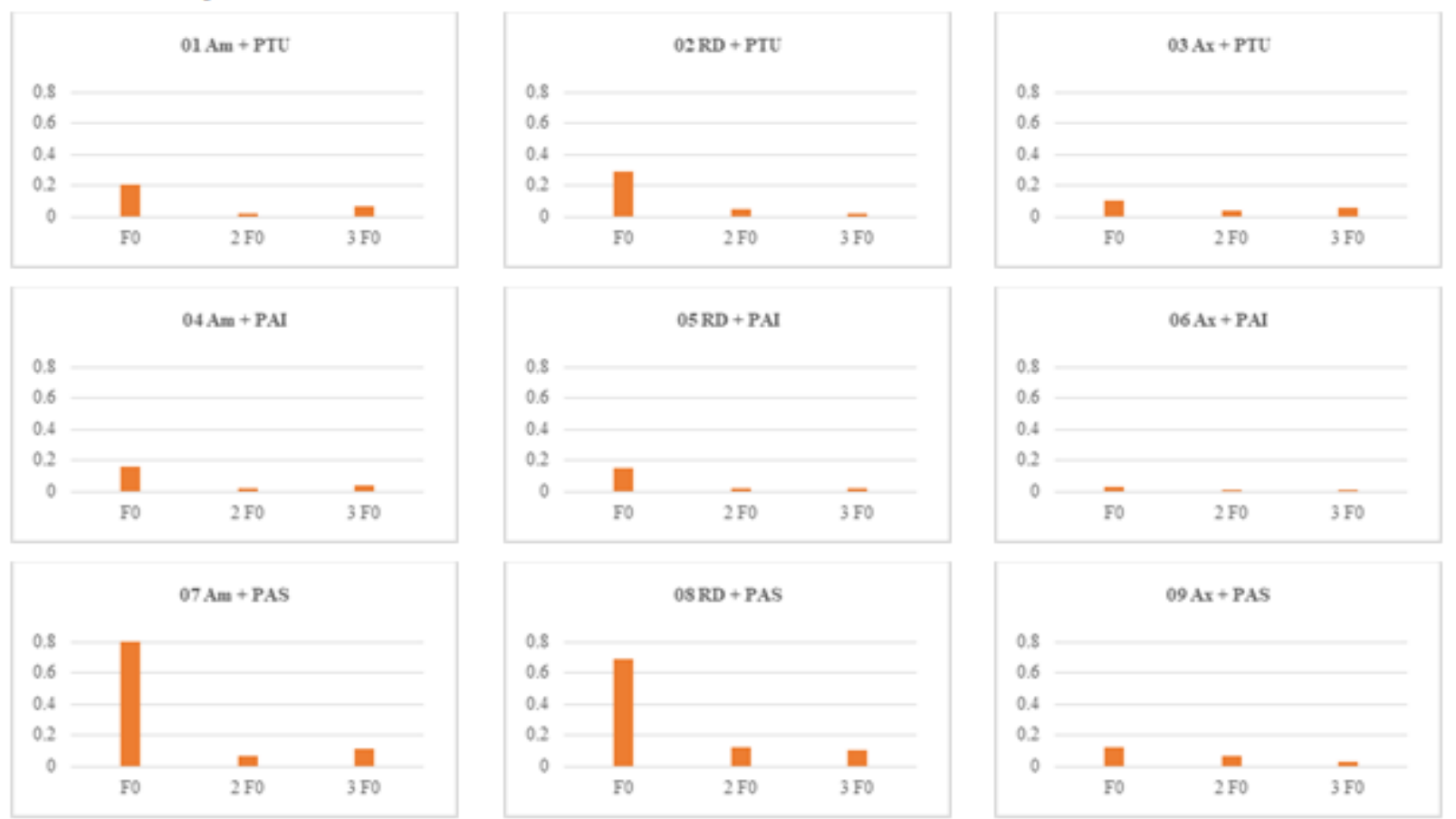

Figure 7 Real vibration spectrum $(\mathrm{mm} / \mathrm{s})$ in MDEMI mode
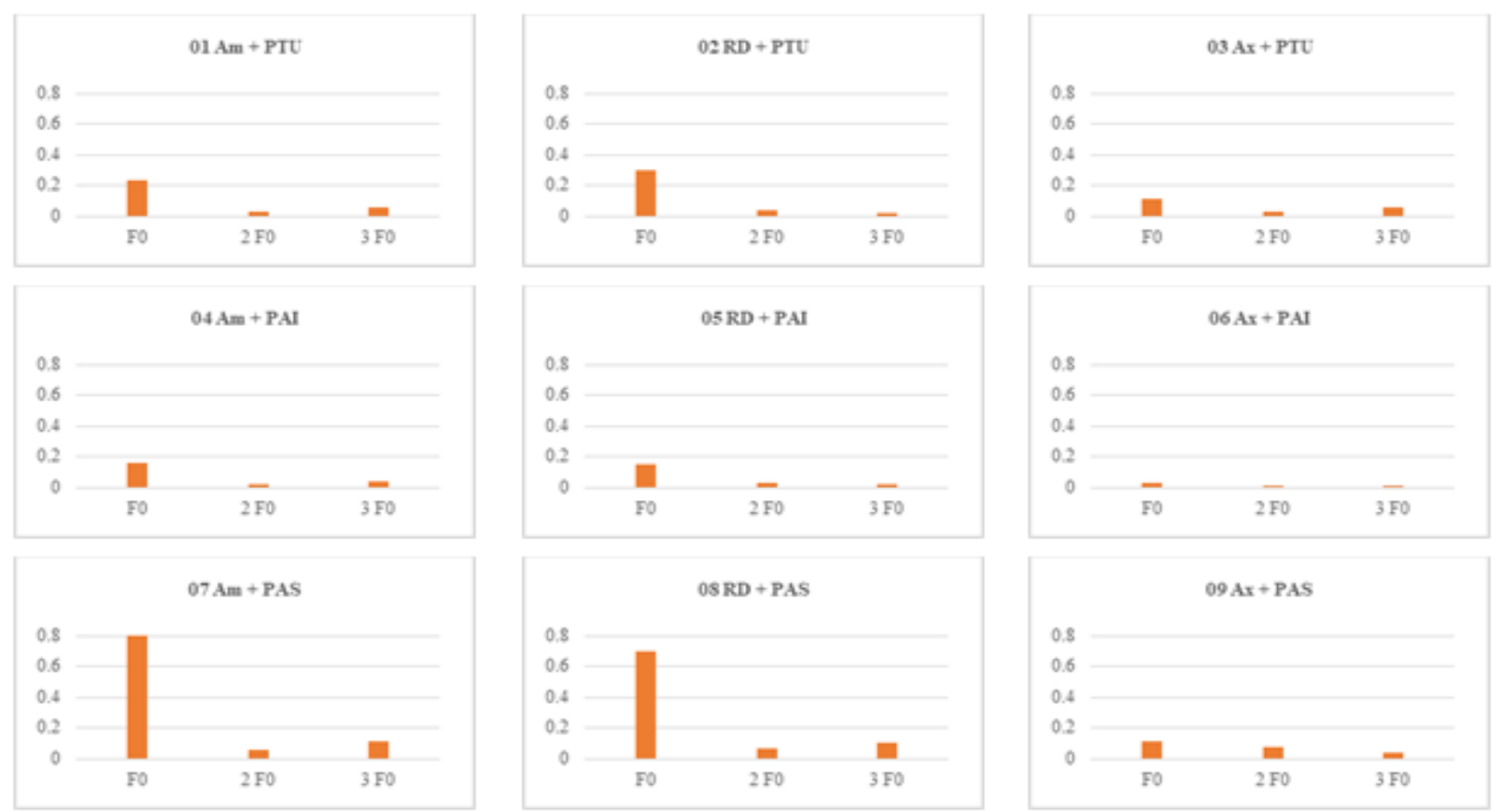

Figure 8 Real vibration spectrum $(\mathrm{mm} / \mathrm{s})$ in MDEMI + Q mode 


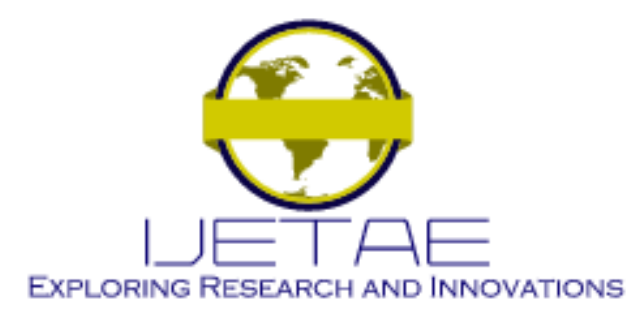

International Journal of Emerging Technology and Advanced Engineering

Website: www.ijetae.com (E-ISSN 2250-2459, Scopus Indexed, ISO 9001:2008 Certified Journal, Volume 11, Issue 11, November 2021)
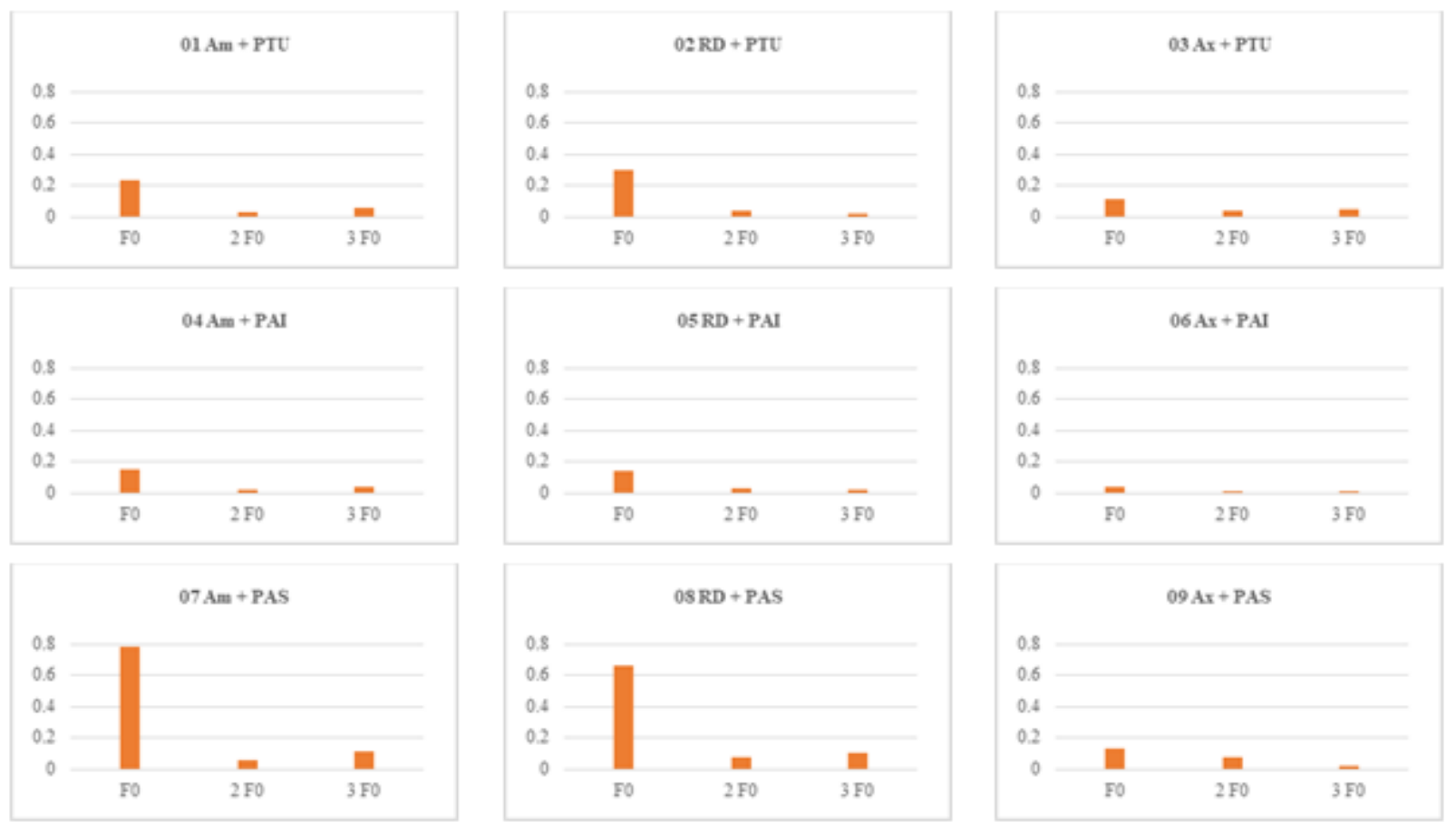

Figure 9 Real vibration spectrum $(\mathrm{mm} / \mathrm{s})$ in MDEMI $-\mathrm{Q}$ mode
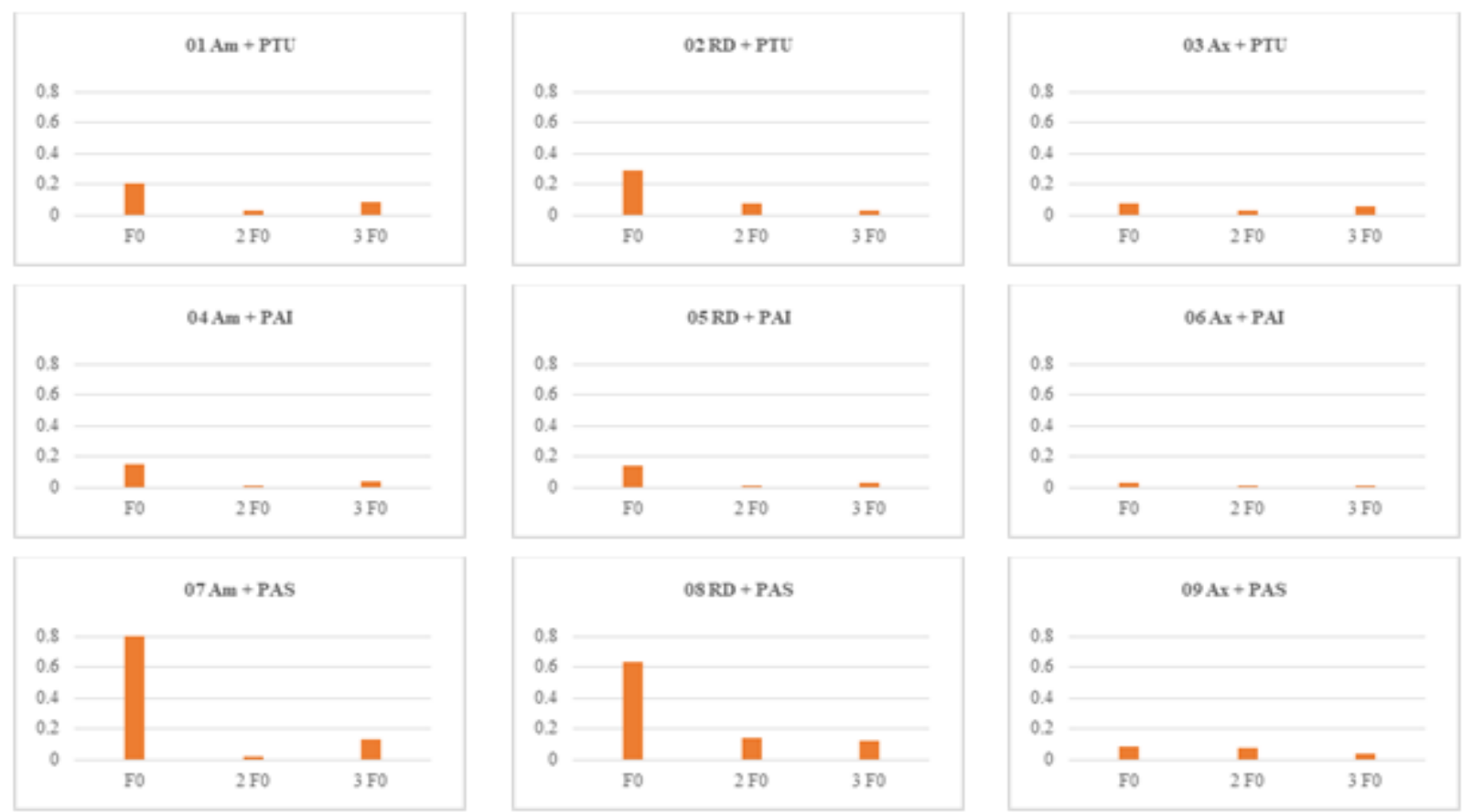

Figure 10 Real vibration spectrum $(\mathrm{mm} / \mathrm{s})$ in M3QUARTS mode 


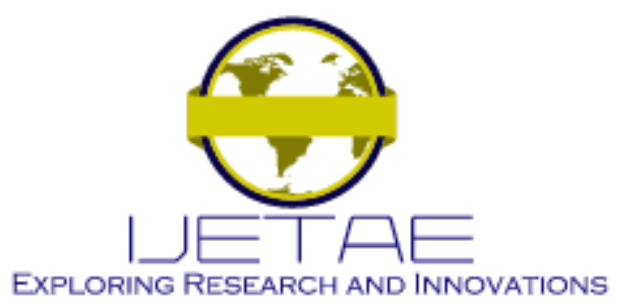

International Journal of Emerging Technology and Advanced Engineering Website: www.ijetae.com (E-ISSN 2250-2459, Scopus Indexed, ISO 9001:2008 Certified Journal, Volume 11, Issue 11, November 2021)
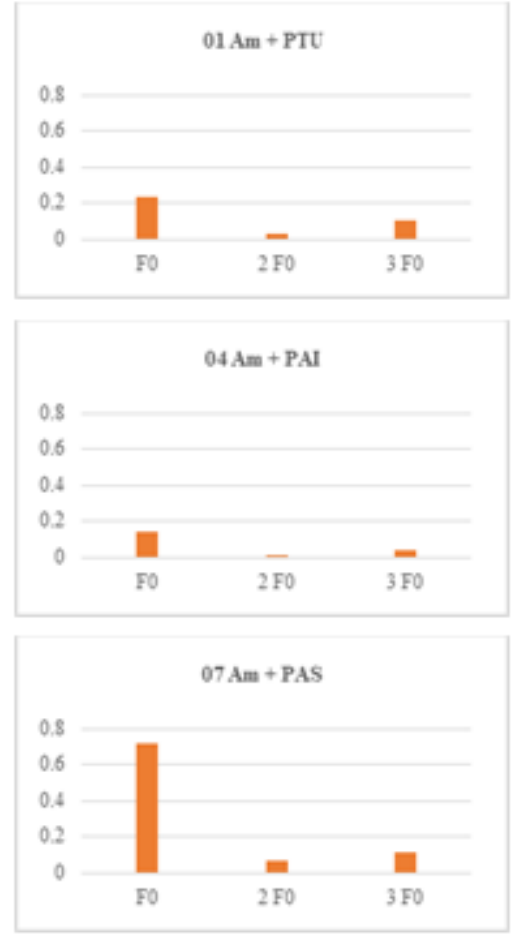
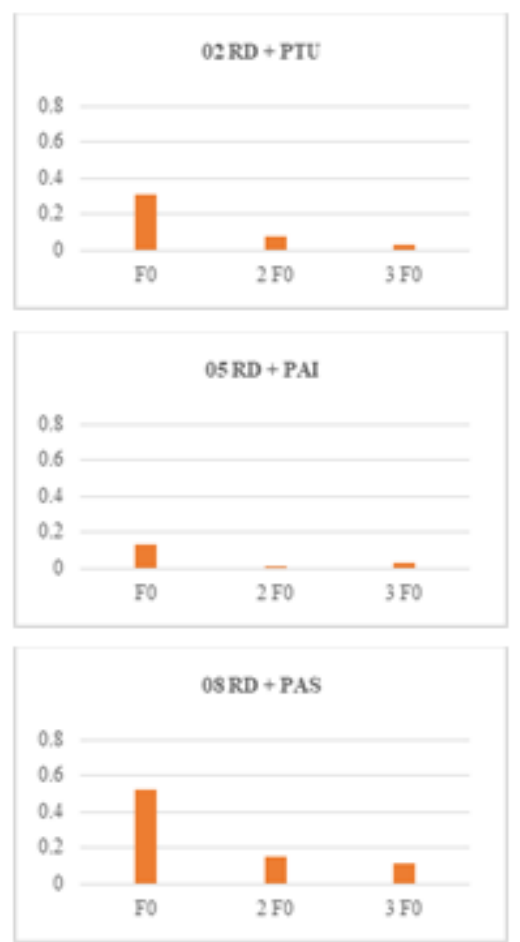
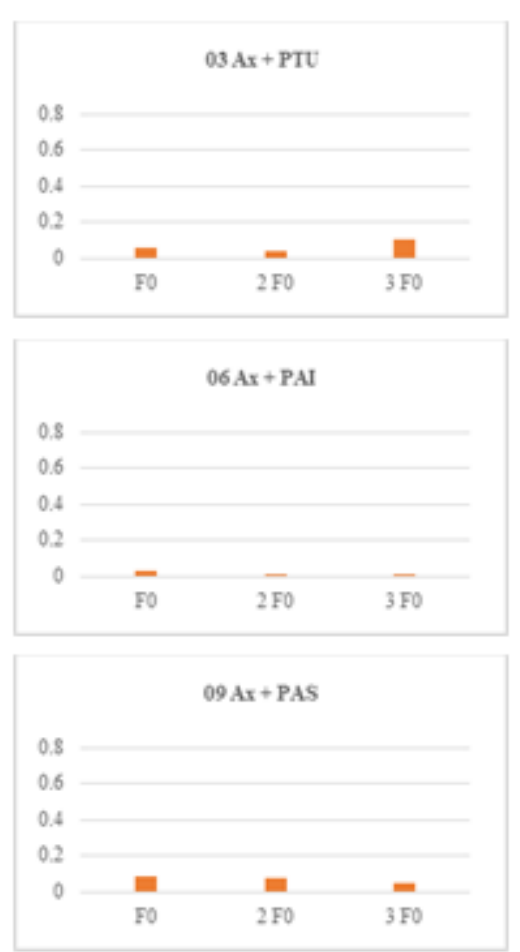

Figure 11 Real vibration spectra $(\mathrm{mm} / \mathrm{s})$ in MPMAX mode

The Figure. 12 represents the evolution of the peak-topeak vibratory displacement indicator $(\mathrm{Spp})$ of the bearings. The movements observed from:

- Turbine bearing (PTU) are of the order of $600 \mu \mathrm{m}$ during half-load tests (MDEMI) (Spp $\max =597 \mu \mathrm{m}$ in MDEMI -Q operating mode);

- Alternator lower bearing (PAI) are acceptable with a max Spp of $250 \mu \mathrm{m}$ in MAVEX operating mode;

- Upper alternator bearing (PAS) are higher, and this is remarkable across all operating modes (between 560 and $573 \mu \mathrm{m}$ ).
The Figure. 13 presents an orbital analysis of the bearings displacements (PTU, PAI and PAS). An eccentricity was observed on the Downstream Side (Av) and Left Bank (RG) of the shaft line of the three bearings during the various tests with the exception of the MAVNE and MAVEX operating modes. During the start-up phase (a duration of $420 \mathrm{~s}$ ), the shaft line remains concentric (Figure. $13(\mathrm{~d})$ ), on the other hand it is eccentric throughout the stopping phase (Figure. 13 (e)). 


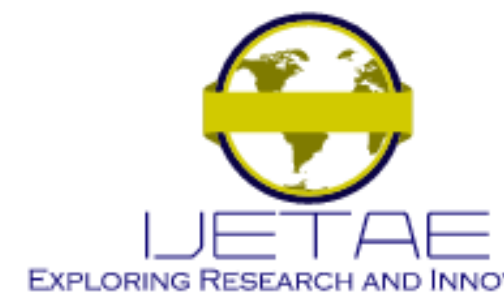

International Journal of Emerging Technology and Advanced Engineering

Website: www.ijetae.com (E-ISSN 2250-2459, Scopus Indexed, ISO 9001:2008 Certified Journal, Volume 11, Issue 11, November 2021)

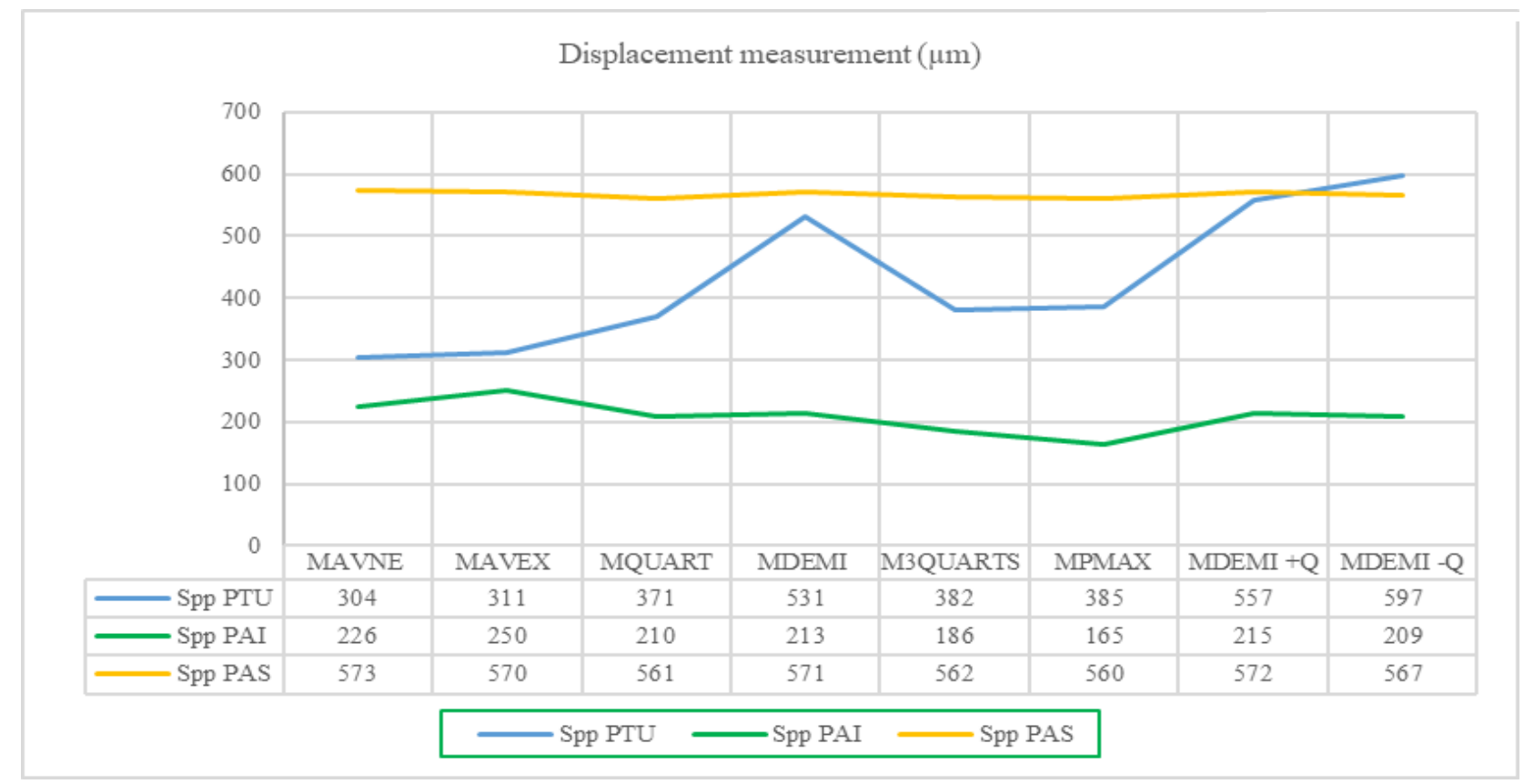

Figure 12 Evolution of the peak-to-peak vibratory displacement indicator (Spp) of the bearings

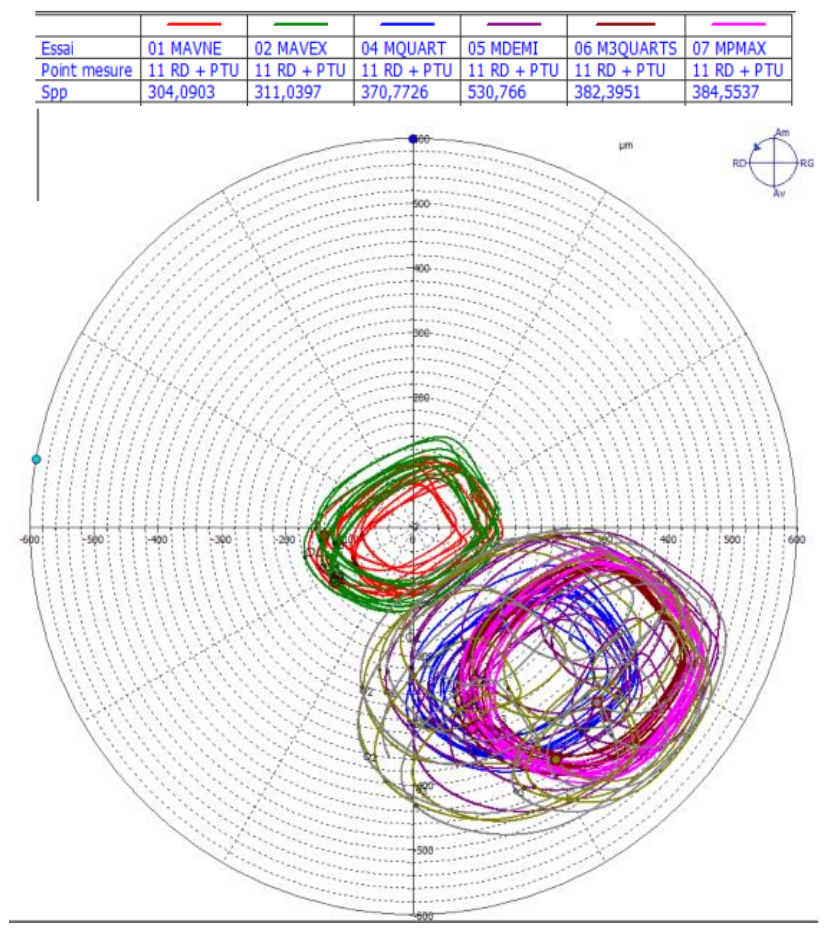

(a) Evolution of the orbits of the turbine bearing (PTU) 


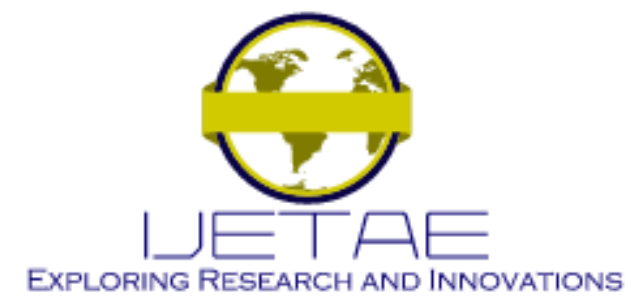

International Journal of Emerging Technology and Advanced Engineering

Website: www.ijetae.com (E-ISSN 2250-2459, Scopus Indexed, ISO 9001:2008 Certified Journal, Volume 11, Issue 11, November 2021)
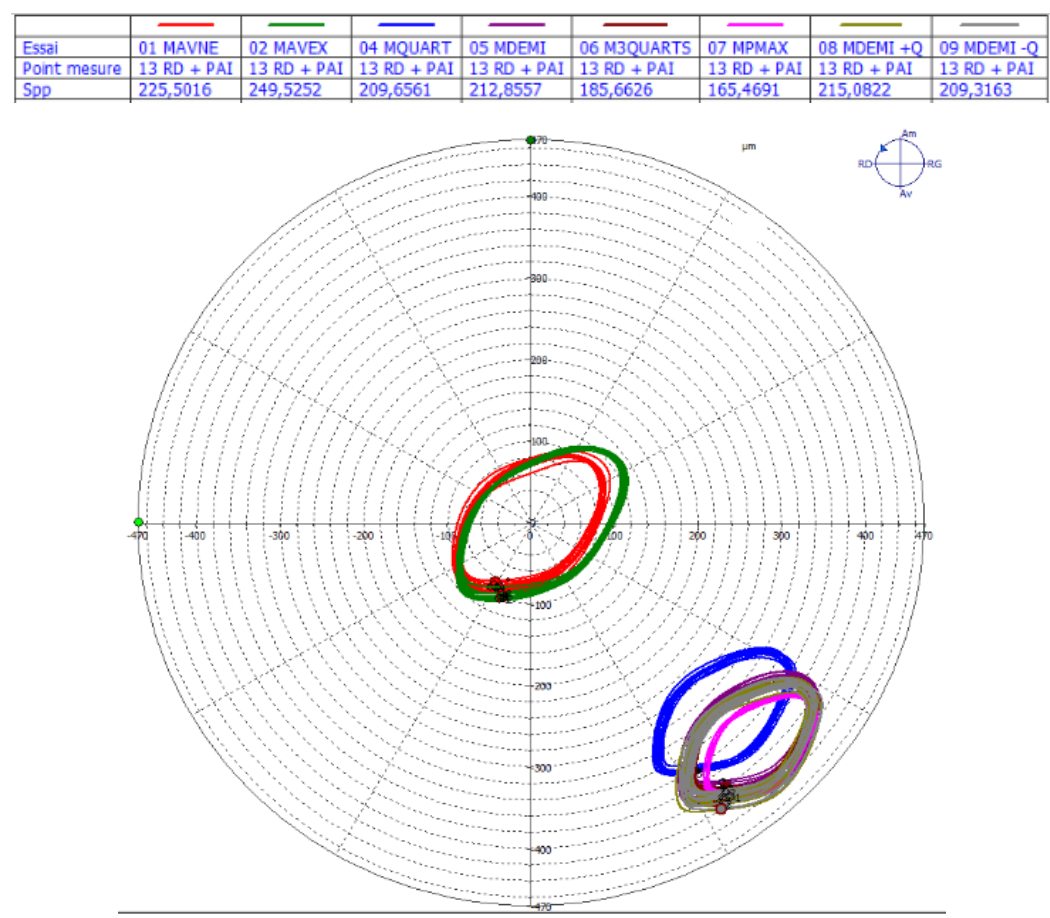

(b) Evolution of the orbits of the lower alternator bearing (PAI)
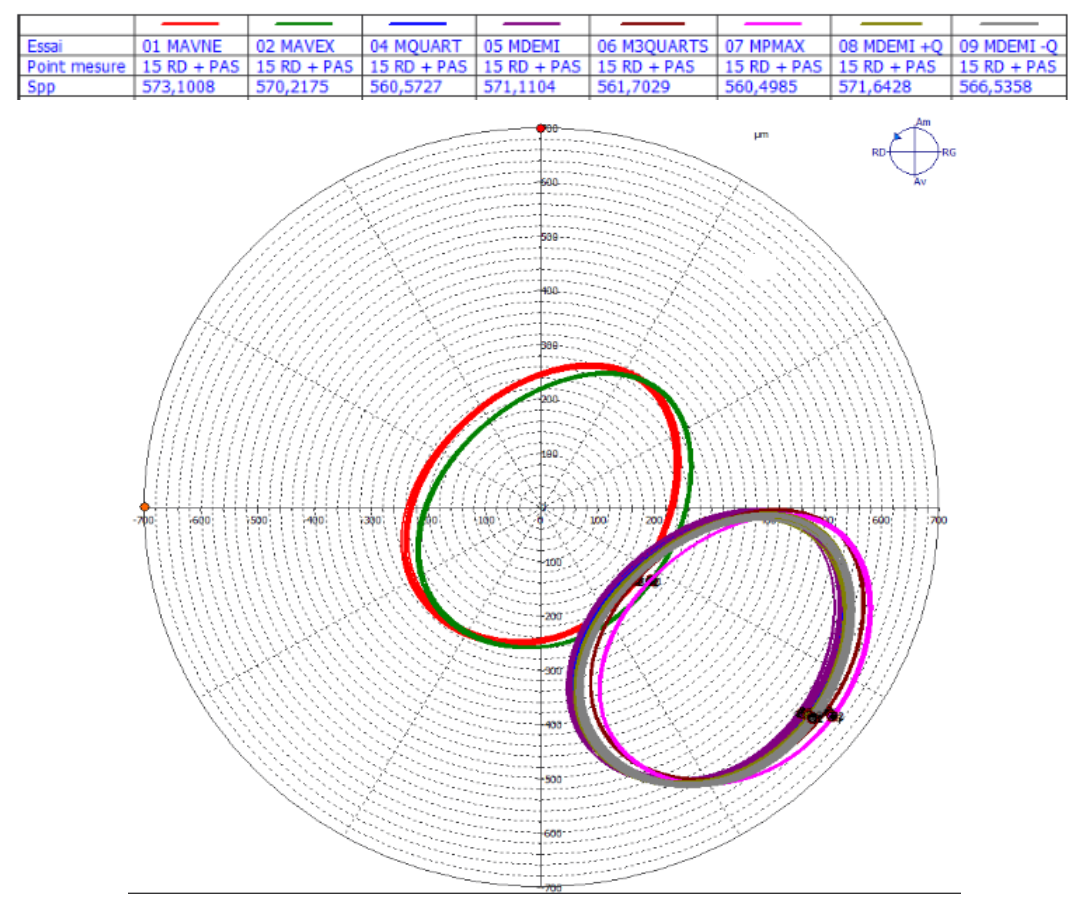

(c) Evolution of the orbits of the upper alternator bearing (PAS) 


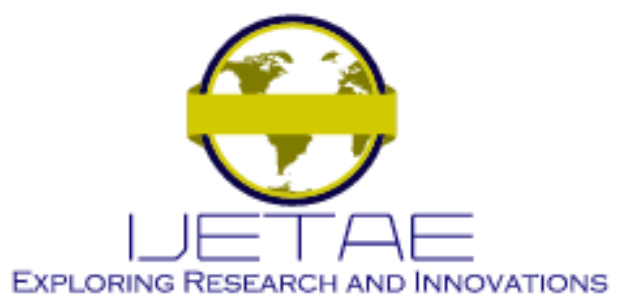

International Journal of Emerging Technology and Advanced Engineering

Website: www.ijetae.com (E-ISSN 2250-2459, Scopus Indexed, ISO 9001:2008 Certified Journal, Volume 11, Issue 11, November 2021)

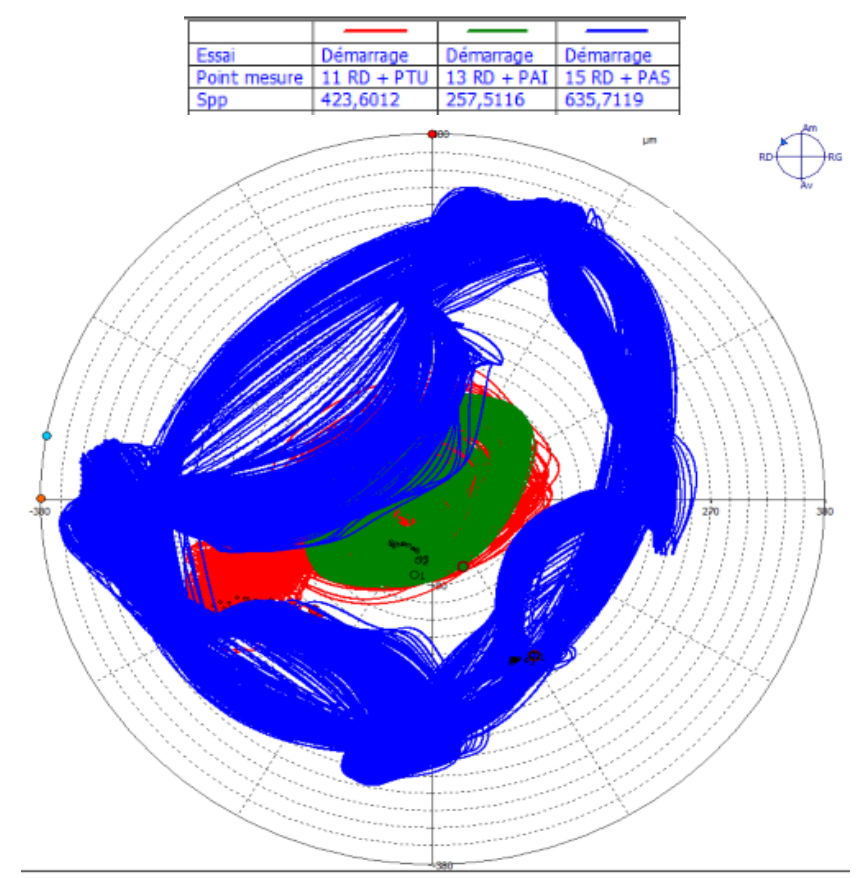

(d) Evolution of the group's orbits during start-up

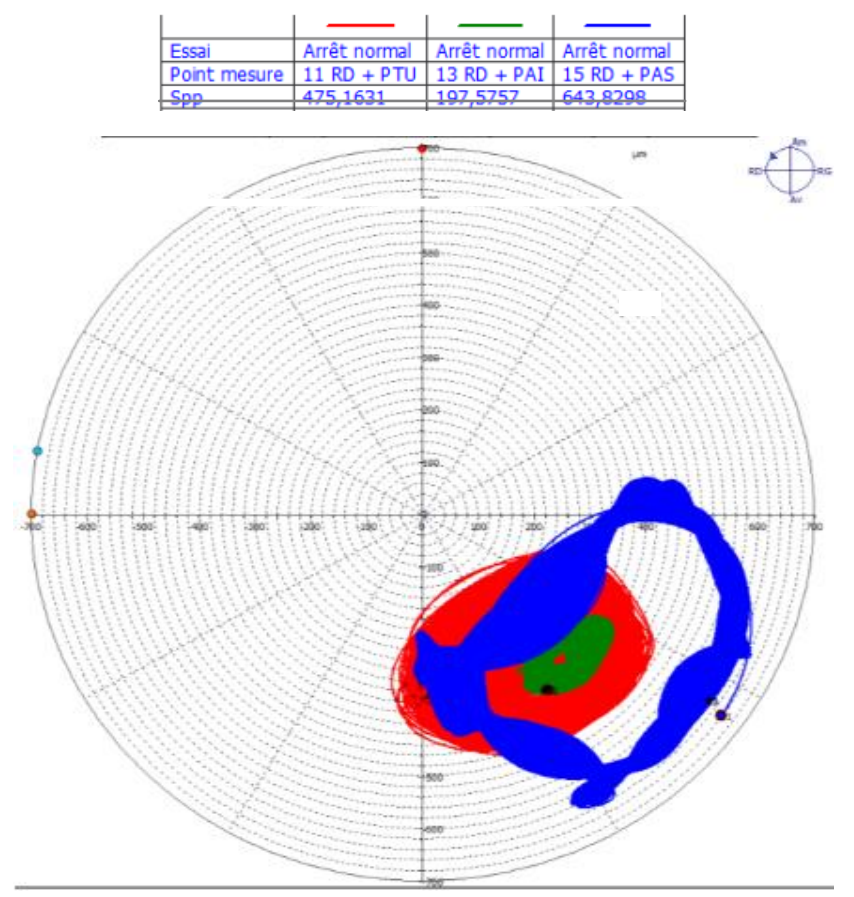

(e) Evolution of the group's orbits during the shutdown

Figure 13 Orbital analysis of the bearings displacements (PTU, PAI and PAS) 


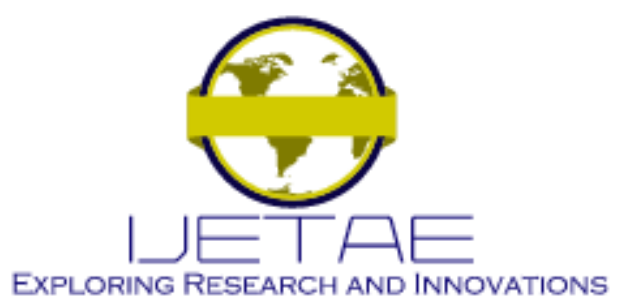

International Journal of Emerging Technology and Advanced Engineering

Website: www.ijetae.com (E-ISSN 2250-2459, Scopus Indexed, ISO 9001:2008 Certified Journal, Volume 11, Issue 11, November 2021)

The study carried out in this research work, which is based on the multi-sensor approach, provided relevant results in order to identify and evaluate the faults of the hydroelectric group. The group has acceptable vibration levels according to the reference of Standard ISO10816-5 [21] (machine that can operate without restriction). Furthermore, the group shaft has an unbalance fault with acceptable values (maximum value of $0.86 \mathrm{~mm} / \mathrm{s}$ ), as well as a misalignment at the level of the upper bearing of the alternator (PAS). The measured displacements are high, the maximum Spp is $597 \mu \mathrm{m}$ on the turbine bearing (PTU), $250 \mu \mathrm{m}$ on the lower alternator bearing (PAI) and $573 \mu \mathrm{m}$ on the upper alternator bearing (PAS). The displacement values respectively classify the bearings in zones D, B, D of Standard ISO 7919-5 (see Table IV). These large displacements are probably linked to an increase in the clearance in the bearings. The turbine bearing exhibits high displacement indicators during the MDEMI operating mode, during tests with variations in the reactant, due to a partial load torch (hydraulic phenomenon known to Francis turbines). This operating regime is to be avoided.

TABLE IV ISO 7919-5 STANDARD [20]

\begin{tabular}{|c|c|c|c|c|}
\hline $333 \mathrm{rpm}$ & A & B & C & D \\
\hline Spp & $<140$ & $<240$ & $<480$ & $>480$ \\
\hline
\end{tabular}

The orbital analysis for the different bearings clearly shows the eccentricity of the center of the shaft on the planes, which exceeds the theoretical clearance values (see Table II). This eccentricity of the center of the shaft does not appear to be of electrical origin because once decoupled during the stop, the shaft does not refocus. All the analyzes do not bring out any friction or shock type anomaly, because the spectra and the orbits do not include subharmonics at $1 / 2$ and $1 / 3$ of the frequency of rotation $F_{0}$.

\section{Conclusion And Perspectives}

Through this article, an approach based on vibratory and orbital analysis has been treated for the diagnosis of the state of health of a hydroelectric group. This technique is considered to be a relevant tool, which is based on the collection of vibration and displacement data using several sensors. The evaluation of the hydroelectric group is verified by the identification of types of faults, displacements at the level of the bearings and the eccentricity of the center of the shaft.
The spectra clearly illustrate the defects observed, namely the predominant defect which is unbalance, and the angular misalignment of the upper bearing of the alternator (PAS). The displacements taken during the tests are high, of which these values classify the bearings in critical zones according to Standard ISO 7919-5. Thus, an eccentricity observed in the shaft line of the hydroelectric group during the orbital analysis of the displacements, during the tests carried out, except for the idle operating modes (excited and not excited). The summary that emerged during this article provides for a check of the games when the group stops. These clearances are observed when checking the concentricity of the group shaft line. The present work will be the track of a modeling of the group whose goal is to predict the failure horizon of an intervention planned by the maintenance department, based on the Neural Networks method to improve and optimize the accuracy of predictions.

\section{REFERENCES}

[1] El. Semma, A. Mousrij, H. Gziri, "Development of a conditional maintenance implementation approach based on vibration analysis", MOSIM 2014, Nov 2014, Nancy, France.

[2] H. Ocak, K. A. Loparo, F. M. Discenzo, "Online tracking of bearing wear using wavelet packet decomposition and probabilistic modeling: A method for bearing prognostics", Journal of sound and vibration, 302, 951-961, 2007.

[3] X. Gu and C. Chen, "Rolling bearing fault signal extraction based on stochastic resonance-based denoising and VMD", International Journal of Rotating Machinery, 2017, Article ID. 3595871, 12 pages, 2017.

[4] C. Li, M. Liang, Y. Zhang, and S. Hou, "Multi-scale autocorrelation via morphological wavelet slices for rolling element bearing fault diagnosis", Mechanical Systems and Signal Processing, 31, 428446, 2012.

[5] C. Li and M. Liang, "Continuous-scale mathematical morphologybased optimal scale band demodulation of impulsive feature for bearing defect diagnosis", Journal of Sound and Vibration, 331, No. 26, 5864-5879, 2012.

[6] P. Nectoux, R. Gouriveau, K. Medjaher, E. Ramasso, B. C. Morello, et al.,"PRONOSTIA: An experimental platform for bearings accelerated degradation tests", IEEE International Conference on Prognostics and Health Management, PHM'12, Jun 2012, Denver, Colorado, United States, 1-8, hal-00719503.

[7] P. H. Rodríguez, J. B. Alonso, M. A. Ferrer, C. M. Travieso, "Application of the Teager-Kaiser energy operator in bearing fault diagnosis", ISA Transactions, 52, No. 2, 278-284, 2013.

[8] Z. He, H. Shao, J. Cheng, X. Zhao, Y. Yang, "Support tensor machine with dynamic penalty factors and its application to the fault diagnosis of rotating machinery with unbalanced data", Mechanical Systems and Signal Processing, 141, July 2020.

[9] H. M. Ertunc and C. Oysu, "Drill wear monitoring using cutting force signals", Mechatronics, 14, 533-548, 2004. 


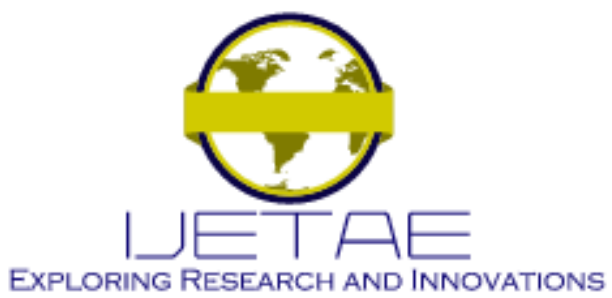

International Journal of Emerging Technology and Advanced Engineering Website: www.ijetae.com (E-ISSN 2250-2459, Scopus Indexed, ISO 9001:2008 Certified Journal, Volume 11, Issue 11, November 2021)

[10] L. Jing, T. Wang, M. Zhao, P. Wang, "An Adaptive Multi-Sensor Data Fusion Method Based on Deep Convolutional Neural Networks for Fault Diagnosis of Planetary Gearbox", Sensors, 17, 414, 2017.

[11] M.S. Safizadeh, and A. Golmohammadi, "Prediction of oil whirl initiation in journal bearings using multi-sensors data fusion", Measurement, 2019.

[12] Y. Meng, L. Lu, J. Yan, "Shaft Orbit Feature Based Rotator Early Unbalance Fault Identification”, Procedia, CIRP 2016, 56, 512-515, 2016.

[13] I. El Adraoui, M. Bouaicha, H. Gziri, M. Zegrari, "Implementation of a Diagnostic Approach Based on Vibration Analysis: Case Study of a Hydroelectric Group", International Journal of Engineering Trends and Technology, 69, issue. 9, 97-106, 2021.

[14] P. Jayaswal, A. K. Wadhwani, K. B. Mulchandani, "Machine fault signature analysis", International Journal of Rotating Machinery, 2008, Article ID. 583982, 10 pages, 2008.

[15] I. El Adraoui, H Gziri, A Mousrij, " Diagnosis and Prognosis of Maintenance Based on Degradation: Case of a Vibratory System", MOSIM2020, Nov 2020, AGADIR (virtual), Morocco.
[16] J. Yan, Y. Hu, C. Guo, “ Rotor unbalance fault diagnosis using DBN based on multi-source heterogeneous information fusion", Procedia Manufacturing, 35, 1184-1189, 2019.

[17] A. Y. Kaltungo, and J. Sinha, "Generic vibration-based faults identification approach for identical rotating machines installed on different foundations", In VIRM 11 - Vibrations in Rotating Machinery, 499-510, 2016.

[18] N. Wang, and D. Jiang, "Vibration response characteristics of a dualrotor with unbalance-misalignment coupling faults: Theoretical analysis and experimental study ", Mechanism and Machine Theory, 125, 207-219, July 2018.

[19] A. Boulanger, and C. Pachaud, "Vibration analysis in maintenance: Monitoring and diagnosis of machines”, Dunod (3rd edition), 2013.

[20] ISO 7919-5 "Mechanical vibration - Evaluation of machine vibration by measurements on rotating shafts", Part. 5, Machine sets in hydraulic power generating and pumping plants, 2005.

[21] ISO 10816-5, "Mechanical vibration - Evaluation of machine vibration by measurements on non-rotating parts", Part. 5, Machine sets in hydraulic power generating and pumping plants, 2000. 